\title{
ABSTRACT
}

\section{Impact of a Supplementation Policy (STOP) on Prescribing Pattern and Cost in a Rural Referral Hospitals of Sabah}

S. Raman ${ }^{1 *}$, Rohani R. N. ${ }^{1}$, Shamsuddin A. L. ${ }^{1}$, Saharun M. R. ${ }^{1}$

${ }^{1}$ Pharmacy Department, Hospital Keningau, Keningau, Sabah

\section{*Corresponding author's email: surge_raj@yahoo.com}

Keywords: supplementation policy, cost, appropriateness

NMRR Research ID: NMRR-18-144-36935
Introduction: In Malaysia, there is an increase in both demand and prescribing of supplements. Such trend raises the likelihood of adverse events and treatment costs. Numerous prescribing policies have been suggested for better utilization of resources. However the adherence and improvement from such policies are yet to be fully characterized. Objective: This study was conducted to determine the impact of a locally developed Supplementation Policy (STOP) on prescribing pattern and cost in Hospital Keningau, Sabah. Methodology: This was a cross-sectional study. An adapted survey was given to all prescribers to investigate their beliefs, attitude and knowledge on dietary supplement. This was followed by implementation of STOP for a period of 2 months. Changes in prescribing pattern and drug cost were measured based on prescriptions collected for 2 weeks prior and after the intervention. Appropriateness of prescription was categorized based on the indication in the National Medication Formulary and agreement from expert panel. Results: 100 prescribers from various disciplines completed the survey. Supplementation prescribing was mostly based on personal clinical experience $(27.6 \%)$, practice $(23.5 \%)$ and patient request (19.4\%). Only $6.1 \%$ claim that their prescribing was based on the indication in National Formulary. Prior to STOP, $11.0 \%(\mathrm{SD}=2.8)$ of total prescription contains a supplement while 94.4\% (SD = 5.3) of them were categorised as not in accordance to formulary. Implementation of STOP showed a significant reduction in 
total prescriptions with supplements (40.3 vs $24.3, p=0.007)$ and those with inappropriate supplementation (38.2 vs $22.2, p=0.003$ ). However, there were no significant changes in terms of supplementation cost (52.94 vs 46.75 , $p=0.617$ ). Conclusion: STOP was beneficial in reducing inappropriate prescribing and changing prescribing patterns. Inappropriate prescribing may have been compounded by lack of availability of nutritional supportservices and pressure from beliefs and expectations for lower socio-economic population. These small improvements are important and significant by taking into consideration the high volume of annual prescribing. 